\title{
Brief Exposure of Embryos to Steroids or Aromatase Inhibitor Induces Sex Reversal in Nile Tilapia (Oreochromis niloticus)
}

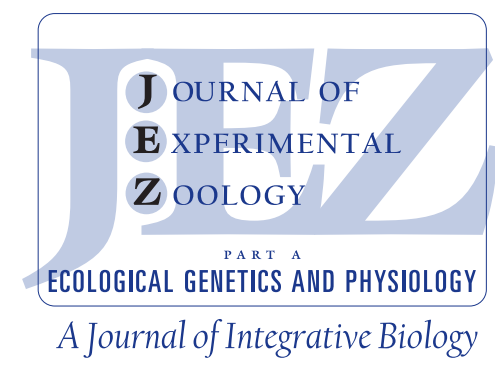

VINCENT GENNOTTE ${ }^{1 *}$, PATRICK MAFWILA KINKELA ${ }^{1}$, BERNARD ULYSSE ${ }^{1}$, DIEUDONNÉ AKIAN DJÉTOUAN ${ }^{1}$, FRÉDÉRIC BERE SOMPAGNIMDI ${ }^{1}$, THOMAS TOMSON ${ }^{2}$, CHARLES MÉLARD ${ }^{1}$, AND CAROLE ROUGEOT ${ }^{1}$

\author{
${ }^{1}$ Aquaculture Research and Education Center (CEFRA), AFFISH-RC, University of Liè, ge, Tihange, \\ Belgium \\ ${ }^{2}$ Centre de Recherche pour la Récupération des Energies Résiduelles, CERER Pisciculture, Tihange, Belgium
}

\begin{abstract}
J. Exp. Zool.

This study aimed to develop sex reversal procedures targeting the embryonic period as tools to study the early steps of sex differentiation in Nile tilapia with $X X, X Y$, and $Y Y$ sexual genotypes. $X X$ eggs were exposed to masculinizing treatments with androgens $(17 \alpha$-methyltestosterone, 11ketotestosterone) or aromatase inhibitor (Fadrozole), whereas XY and YY eggs were subjected to feminizing treatments with estrogen analog ( $17 \alpha$-ethynylestradiol). All treatments consisted of a single or double 4-hr immersion applied between 1 and 36 hour post-fertilization (hpf). Concentrations of active substances were 1000 or $2000 \mu \mathrm{g} \mathrm{I}^{-1}$ in $X X$ and $X Y$, and 2000 or $6500 \mu \mathrm{g} \mathrm{I}^{-1}$ in $Y Y$. Masculinizing treatments of XX embryos achieved a maximal sex reversal rate of $10 \%$ with an exposure at $24 \mathrm{hpf}$ to $1000 \mu \mathrm{g} \mathrm{I} \mathrm{I}^{-1}$ of 11 -ketotestosterone or to $2000 \mu \mathrm{g} \mathrm{I}^{-1}$ of Fadrozole. Feminization of $X Y$ embryos was more efficient and induced up to $91 \%$ sex reversal with an exposure to $2000 \mu \mathrm{g} \mathrm{I}^{-1}$ of $17 \alpha$-ethynylestradiol. Interestingly, similar treatments failed to reverse $Y Y$ fish to females, suggesting either that a sex determinant linked to the $Y$ chromosome prevents the female pathway when present in two copies, or that a gene present on the $X$ chromosome is needed for the development of a female phenotype. J. Exp. Zool. 323A:31-38, 2015. (c) 2014 Wiley Periodicals, Inc.

How to cite this article: Gennotte V, Mafwila Kinkela $P$, Ulysse B, Akian Djétouan D, Bere Sompagnimdi F, Tomson T, Mélard C, Rougeot C. 2015. Brief exposure of embryos to steroids or aromatase inhibitor induces sex reversal in Nile tilapia (Oreochromis niloticus). J. Exp. Zool. 323A:31-38.
\end{abstract}

Sex reversal techniques are largely used for the control of sex in fish farming and in fundamental studies on sex determinism mechanisms. In tilapia aquaculture, all-male populations are preferred because they achieve higher growth rate and prevent uncontrolled reproduction (Beardmore et al., 2001). Due to its efficiency and simplicity, one of the most common practices used to produce mono-sex populations of tilapia or to obtain males and females with particular sexual genotypes is the sex reversal through the dietary administration of sex steroids during the sensitive period of sex differentiation, usually from 10 to 38 days post-fertilization (dpf) (Phelps and Popma, 2000). Sex reversal treatments are also useful to explore the role played by genetic
Grant sponsor: FRIA-FNRS (Fonds pour la Formation à la Recherche dans I'Industrie et dans l'Agriculture); grant sponsor: ARES-CCD (Académie de Recherche et d'Enseignement Supérieur - Comission de la Coopération au Développement).

Conflicts of interest: None.

*Correspondence to: Gennotte Vincent, Aquaculture Research and Education Centre, AFFISH-RC, University of Liege, Chemin de la Justice 10, B-4500 Tihange, Belgium. E-mail: vgennotte@ulg.ac.be

Received 14 July 2014; Revised 27 August 2014; Accepted 28 August 2014

DOI: $10.1002 /$ jez.1893

Published online 5 November 2014 in Wiley Online Library (wileyonlinelibrary.com). 
and endocrine factors involved in the mechanisms of sex determinism and differentiation.

In fish, a major sex-determining gene similar to the mammalian Sry was identified in a few species, but not in the Nile tilapia Oreochromis niloticus (Kikuchi and Hamaguchi, 2013). In this species, a sex-specific expression of genes potentially involved in sexual differentiation was reported in the gonad (foxl2, forkhead transcription factor L2; cy19a1a, cytochrome P450, family 19, subfamily A, gonad aromatase; $d m r t$, doublesex and mab-3-related transcription factor 1) (Ijiri et al., 2008) and in the brain ( $\mathrm{amh}$, anti-Müllerian hormone) (Poonlaphdecha et al., 2011) from 9-10 dpf but not deeply investigated earlier during the embryonic and larval development. Classically, sex reversal treatments override the natural process of sex differentiation by acting after $10 \mathrm{dpf}$ on mechanisms taking place during the gonad morphogenesis. The masculinizing hormone $17 \alpha$-methyltestosterone (MT) was reported to up-regulate $d m r t 1$, a gene involved in testicular differentiation, from $19 \mathrm{dpf}$ in XX tilapia (Kobayashi et al., 2008). Similarly, administration of $17 \alpha$-ethynylestradiol (EE2) to XY fry induced the ovarian differentiating pathway by repressing $d m r t 1$ and promoting the expression of cyp 19a 1a at $19 \mathrm{dpf}$ (Kobayashi et al., 2003, 2008).

However, an increasing body of evidence gathered in different species argue for a precocious initiation of the differentiation pathway that could occur in the brain or in the primordial germ cells before the development of the gonad (Tsai et al., 2000; D'Cotta et al., 2001; Kobayashi and Iwamatsu, 2005; Kobayashi et al., 2008; Rougeot et al., 2008a,b; Blázquez and Somoza, 2010). Therefore, it is particularly interesting to target sex reversal treatments on early developmental stages in order to study the upstream mechanisms and trace the sex determinism cascade up to the major determinants. During ontogenesis, the brain starts to morphologically differentiate from 31 hour post-fertilization (hpf) and the primordial germ cells can be identified from $46 \mathrm{hpf}$ in Nile tilapia (Morrison et al., 2001). Then, primordial germ cells migrate to the genital ridge to form a gonadal primordium by the 7th dpf (Kobayashi et al., 2003). Based on the assumption that the first steps of molecular sex differentiation would occur during these precocious developmental events, it could be possible to modify the sex determinism by treatments applied during the embryonic period.

In medaka, Oryzias latipes, successful feminizing and masculinizing sex inversions were performed by brief exposure of freshly fertilized eggs to $17 \beta$-estradiol for $24 \mathrm{hr}$ (Iwamatsu et al., 2005; Kobayashi and Iwamatsu, 2005), and preovulatory oocytes to $17 \alpha$-methyldihydrotestosterone for $10 \mathrm{hr}$ (Iwamatsu et al., 2006), respectively. Unlike tilapia, the major sexdeterminant $(d m y)$ was identified in medaka (Matsuda et al., 2002), but interestingly these two species have similar sex determinism systems and morphogenesis during sex differentiation (Siegfried, 2010), suggesting that such precocious treatments could be efficiently applied in tilapia. In Mozambique tilapia (Oreochromis mossambicus), Rosenstein and Hulata, ('92) tested various treatment schemes with a double immersion (of 2-28 hr) of eggs at 2 and $4 \mathrm{dpf}$ in $17 \beta$-estradiol solutions (200-1500 $\mu \mathrm{g}^{-1}$ ) but did not observe any feminizing effect. Using more prolonged treatments (from fertilization to hatching) with EE2 $\left(500 \mu \mathrm{g} \mathrm{l}^{-1}\right)$ and MT $\left(1000 \mu \mathrm{g}^{-1}\right)$ in O. niloticus, Rougeot et al. (2008a) obtained up to 79\% of feminization and $20 \%$ of masculinization. However, this procedure is not the most appropriate to study the embryonic developmental events as the prolonged exposure led to an important accumulation of hormones that could act by a delayed effect on the process of gonad differentiation in fry. Characterization of the EE2 clearance profile in XY fish submitted to such a feminizing treatment revealed very high extra-physiological concentrations (more than $5000 \mathrm{ng} \mathrm{g}^{-1}$ ) of EE2 in fry at the onset of the period of gonadal differentiation (10 dpf) (unpublished data).

The objective of the present research was to develop sex reversal procedures in Nile tilapia using brief immersion treatments applied on the first stages of development in order to focus the action of hormones only on embryogenesis. Different masculinizing and feminizing schemes, varying in active substances, concentrations and moments of application, were tested on XX, XY, and YY spawns, respectively, to identify the most efficient procedures that might be used to study the early mechanisms of sex differentiation.

\section{MATERIALS AND METHODS}

Reproduction and Egg Incubation

Nile tilapia 0 . niloticus (Lake Manzala strain) originated from the Research and Education Center in Aquaculture (CEFRA), University of Liège (Belgium). Different full-sib families were produced by artificial reproduction (Gennotte et al., 2012). XX spawns were obtained by crossing $X X$ males with $X X$ females, $X Y$ spawns by crossing YY males with XX females, and YY spawns by crossing YY males with YY females. Broodstock fish were individually stocked in $125-\mathrm{l}$ aquaria at $27^{\circ} \mathrm{C}$ with a $14 \mathrm{hr}$ light/ $10 \mathrm{hr}$ darkness photoperiodic regime. Fish were fed at satiation with special broodstock commercial tilapia diet (45\% proteins, 5\% lipids, Coppens-The Netherlands). After artificial fertilization, eggs were counted, distributed in different batches according to treatments and incubated in $1.51 \mathrm{Zug}$ bottle at $27^{\circ} \mathrm{C}$. Fertilization rate was evaluated on 100 eggs after the first mitotic cleavage ( $2 \mathrm{hpf}$ ) (Morrison et al., 2001).

Experiments were carried out according to the guidelines of the University of Liège ethical committee and the European animal welfare recommendations.

Hormone and Aromatase Inhibitor Solutions

Steroid hormones $17 \alpha$-ethynylestradiol (EE2), 17 $\alpha$-methyltestosterone (MT), 11-ketotestosterone (11KT), and the aromatase 
inhibitor Fadrozole (Fa) were purchased from Sigma-Aldrich. Hormones and Fa were dissolved in 100\% ethanol to prepare 1000 -fold concentrated stock solutions and stored at $4{ }^{\circ} \mathrm{C}$. For immersion treatments, $1 \mathrm{~mL}$ of stock solution was added to $1 \mathrm{l}$ of hatchery water. Control groups were incubated in 1:1000 ethanol.

\section{Hormonal Treatments}

Feminizing and masculinizing treatments consisted of a single or a double immersion in hormonal or Fa solutions. All immersions lasted $4 \mathrm{hr}$. Treatments were performed at different stages of development from 1 to $36 \mathrm{hpf}$. Eggs were transferred from the Zug bottle into a 11 glass beaker filled with hatchery water and maintained in a thermostatic bath at $27^{\circ} \mathrm{C}$. One milliliter of stock solution (ethanol for control groups) was added to the water. During incubation, water was oxygenated by an air diffuser. After $4 \mathrm{hr}$ of immersion, eggs were netted, gently soaked up and rinsed in six different baths to remove hormone residues. The first three baths contained 1:1000 ethanol and the next three only hatchery water. Control groups were handled in the same way. After rinsing, eggs were replaced into the hatchery.

A total of 10 different masculinizing treatments were tested on XX spawns, and 6 and 5 feminizing treatments on XY and YY spawns, respectively. XX eggs were treated with MT (1000 and $2000 \mu \mathrm{g} \mathrm{l}^{-1}$ ), an aromatizable synthetic androgen, 11KT (1000 and $2000 \mu \mathrm{g} \mathrm{l}^{-1}$ ), a non-aromatizable natural androgen, and $\mathrm{Fa}$ (1000 and $2000 \mu \mathrm{g}^{-1}$ ), a non-steroidal inhibitor of aromatase, the enzyme that converts androgens into estrogens. XY and YY eggs were treated with EE2 (2000 and $6500 \mu g \mathrm{l}^{-1}$ ), a synthetic estrogen.

The concentrations of hormones used in XX and XY treatments were based on the literature (Gilling et al., '96; Kobayashi et al., 2003; Wassermann and Afonso, 2003) and on our previous experiments of egg immersion (Rougeot et al., 2008a). In YY treatments a first concentration of EE2 equal to the XY treatments was tested, and a second concentration increased in the same proportion as EE2 concentrations used in dietary hormonal treatments (150 $\mathrm{mg} \mathrm{kg}^{-1}$ for XY and $500 \mathrm{mg} \mathrm{kg}^{-1}$ for YY) in our laboratory (unpublished data). As a differential timing of sex differentiation can be suspected in YY compared to XY (Herrera and Cruz, 2001), different moments of treatment application were tested in YY. Hormone and Fa concentrations, and the moment of application of each treatment figure in the result tables (Tables 1-3).

Each spawn was divided into several batches receiving different treatments and a control group for each moment of treatment application. In YY groups immersed in a $6500 \mu \mathrm{g}$ EE2 $\mathrm{l}^{-1}$ solution at different moments, only one control group immersed at $24 \mathrm{hpf}$ was used. The number of fertilized eggs per batch and the number of spawns per treatment ranged from 78 to 1371 and from 2 to 8 , respectively.

MT and EE2 are routinely used in our laboratory for the feminization of XX and the masculinization of XY and YY fry, respectively by dietary administration (from 10 to $40 \mathrm{dpf}$, XX: $65 \mathrm{mg} \mathrm{MT} \mathrm{kg}^{-1}$ food; XY: $150 \mathrm{mg}$ EE2 $\mathrm{kg}^{-1}$ food; YY: $500 \mathrm{mg}$ EE2 $\mathrm{kg}^{-1}$ food). These treatments succeed in $94-100 \%$ of sex reversal (unpublished data).

\section{Juvenile Rearing and Sex-Ratio Analysis}

At $8 \mathrm{dpf}$, larvae were counted in order to calculate the survival rate $(=100 \times \mathrm{n}$ larvae/n fertilized eggs $)$ and transferred into 50-1 aquaria $\left(27^{\circ} \mathrm{C}\right)$. From $10 \mathrm{dpf}$, fish were fed close to satiation six times a day with a commercial tilapia diet (47\% proteins, $8 \%$ lipids, Coppens-The Netherlands). Phenotypic sex was determined by the acetocarmine squash method (Guerrero and Shelton, '74) at $90 \mathrm{dpf}$. Fish were euthanized by overdose (500 $\mathrm{mg} \mathrm{l}^{-1}$ ) of benzocaine (Sigma-Aldrich) and a piece of gonad was microscopically examined after acetocarmine coloration. The number of sexed fish per batch ranged from 22 to 121 $($ median $=74)$, from 8 to $124($ median $=50)$ and from 7 to 101 (median $=69$ ) for XX, XY, and YY, respectively. Adding together the different spawns, the overall number of sexed fish per treatment ranged from 69 to 553.

\section{Data Analysis}

Survival (at $8 \mathrm{dpf}$ ) and sex reversal rates are expressed as the overall value and the total range (minimum and maximum) of all the spawns exposed to the same treatment. Sex ratios and survival of the treated groups were compared against the values of their corresponding control groups using the $2 \times 2$ contingency chi-square $\left(\chi^{2}\right)$ test $(d f=1)$. Values were considered as significant at $P<0.05$.

\section{RESULTS}

XX Masculinization Experiments (Table 1)

At $8 \mathrm{dpf}$, survival rates in XX spawns ranged from 22 to $86 \%$ and from 25 to $64 \%$ in treated and control groups, respectively. Overall survival values were significantly higher in batches exposed to MT in a single immersion (at 1 or $24 \mathrm{hpf}$ ) (from 48 to $61 \%$ ) than in their respective controls (39-43\%). In fish submitted to a double immersion (at 1 and $24 \mathrm{hpf}$ ), survival was similar in control and treated batches (from 35 to 42\%). In $11 \mathrm{KT}$ and $\mathrm{Fa}$ treatments, overall survival was 59\% in controls and ranged from 51 to $70 \%$ in treated groups with significantly higher values in fish exposed to $1000 \mu \mathrm{g} \mathrm{l}^{-1}$ of $11 \mathrm{KT}$ and $\mathrm{Fa}$ and a lower value in fish exposed to $2000 \mu \mathrm{g} 11 \mathrm{KT}^{-1}$.

All the XX control fish were females as expected. None of the MT treatments induced a significant deviation of the sex-ratio. In one spawn, immersion in $1000 \mu \mathrm{g} \mathrm{l^{-1 }}$ of MT at 1,24 , and $1+24 \mathrm{hpf}$, respectively induced $8.1,8.3$, and $9.1 \%$ of males but the numbers of sexed fish were low in these batches $(n<37)$ and deviations were not significant. On the contrary, treatments with $11 \mathrm{KT}$ or Fa significantly induced up to $10 \%$ of sex reversal. Overall percentages of males in $11 \mathrm{KT}$ and $\mathrm{Fa}$ treatments were 


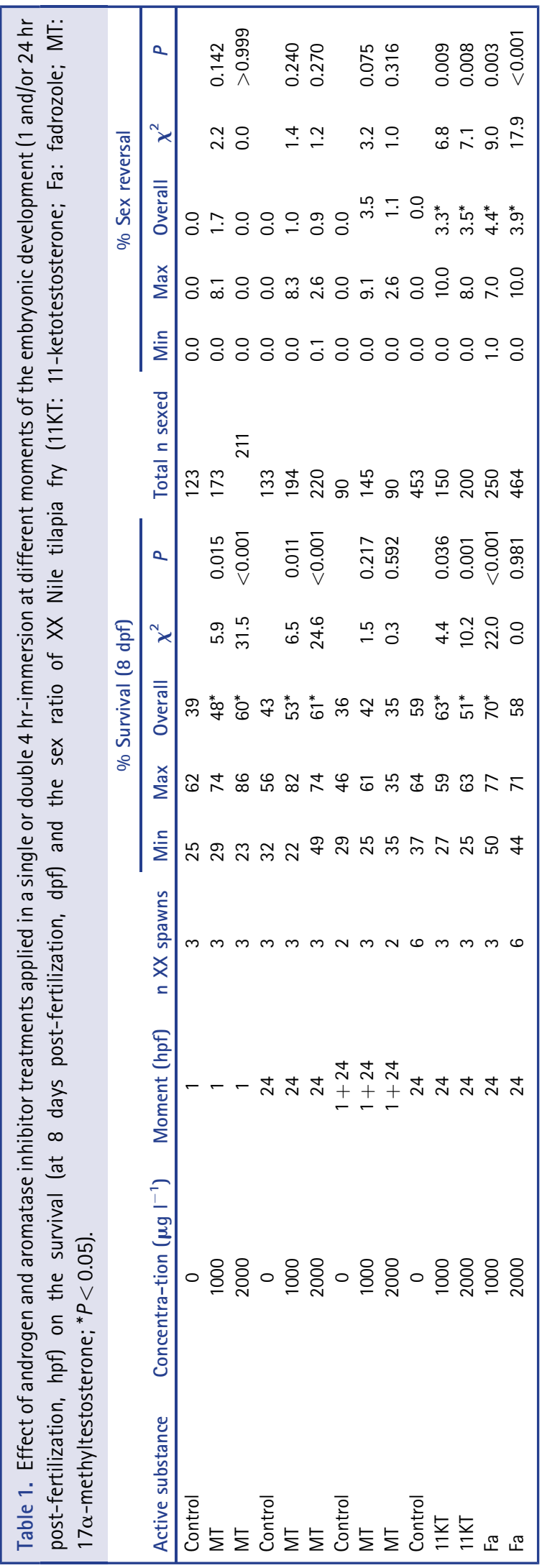

similar in 1000 and $2000 \mu \mathrm{g} \mathrm{l^{-1 }}$ immersions (3.3 and 3.5\%, 4.4 and $3.9 \%$ for $11 \mathrm{KT}$ and $\mathrm{Fa}$, respectively) and significantly different from the control groups.

XY Feminization Experiments (Table 2)

Survival rates in XY spawns ranged from 26 to 85\% and from 28 to $86 \%$ in EE2-treated and control groups, respectively. Overall survival values were above $60 \%$ in groups treated with a single immersion at 1 or $24 \mathrm{hpf}$ and not statistically different from the control groups, except for the group treated in a $1000 \mu \mathrm{g} \mathrm{l}^{-1}$ solution at $1 \mathrm{hpf}$ that displayed a higher survival (72\%). Double immersion at 1 and $24 \mathrm{hpf}$ led to lower survival. In this treatment, survival of hormone-exposed fish (32-33\%) was significantly lower than the controls (44\%).

Sex-ratio of the XY control groups was 100\% male as expected. A significant sex reversal effect $(P<0.001)$ was observed in all the EE2 treatments. Fish exposed to EE2 at 1, 24, and $1+24 \mathrm{hpf}$ showed increasing overall sex reversal rates: $9.9-26.6 \%$ at $1 \mathrm{hpf}, 48.0-48.6 \%$ at $24 \mathrm{hpf}$, and $65.9-65.2 \%$ at $1+24 \mathrm{hpf}$ for 1000 and $2000 \mu \mathrm{g} \mathrm{l}^{-1}$, respectively. The efficiency of the treatment was related to the hormone concentration only in the treatment applied at $1 \mathrm{hpf}$. The maximum sex reversal rate $(91 \%)$ was observed in a spawn immersed at $24 \mathrm{hpf}$ in a $2000 \mu \mathrm{g} \mathrm{l^{-1 }}$ solution.

\section{YY Feminization Experiments (Table 3)}

In treatment of YY at $6500 \mu \mathrm{g}$ EE2 $1^{-1}$, overall survival was greatly affected in fish immersed at $12 \mathrm{hpf}(24 \%$ vs. $64 \%$ in the controls). For the treatment applied later (18, 24, and $36 \mathrm{hpf}$ ), survival was similar to the controls. Survival values are missing for the treatment at $2000 \mu \mathrm{g} \mathrm{l^{-1 }}$.

All the YY control fish were males as expected. None of the EE2 treatment significantly skewed sex-ratio in any of the spawns.

\section{DISCUSSION}

Our results demonstrate that brief $4 \mathrm{hr}$-immersions of fertilized eggs in androgen, aromatase inhibitor, and in estrogen solutions applied between 1 and $24 \mathrm{hpf}$ can induce significant sex reversal in XX and XY Nile tilapias. Feminization of XY with EE2 is 10 to 15 -fold more efficient than masculinization of XX with $11 \mathrm{KT}$ or Fa. No significant masculinizing effect was observed with MT. Interestingly, estrogen treatments failed to reverse the sex of YY fish, even at higher doses.

Regarding the wide variety of steroid compounds used for sex reversal in fish, different efficiencies arise from different affinities for their receptors, activities of the steroid-receptor complexes, and their metabolism (Devlin and Nagahama, 2002). Since all the steroids and the aromatase inhibitor used in the present study have proven their high potency for sex reversal in fish when administered during gonadal differentiation (Pandian and Sheela, '95; Devlin and Nagahama, 2002), particularly in tilapia (except 11KT that was used for the first time in Nile tilapia 


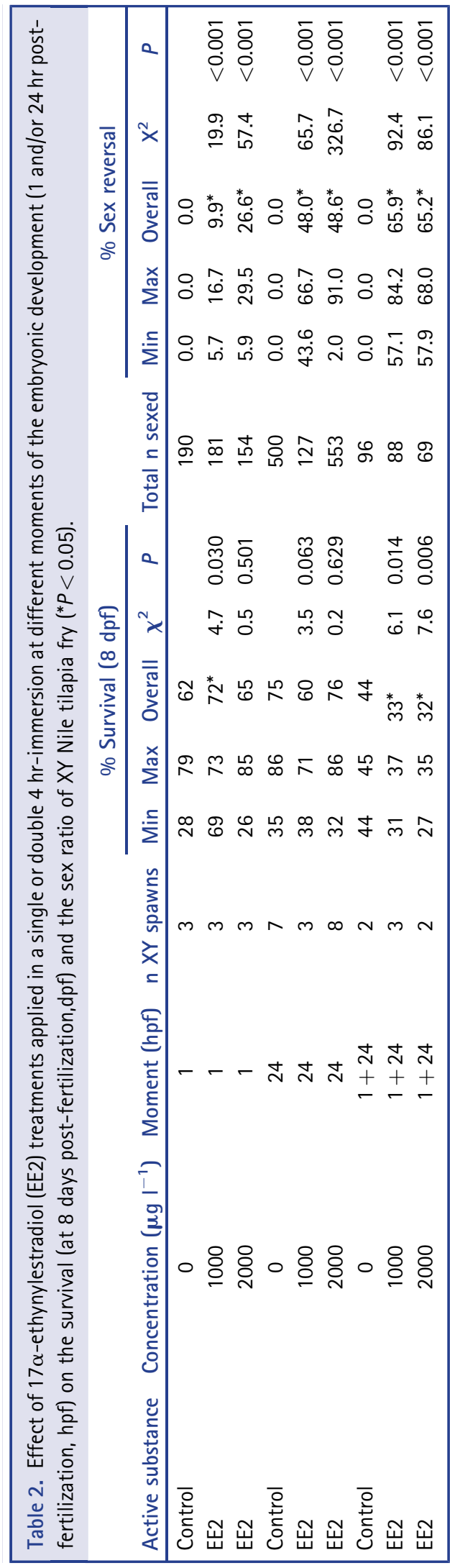

in our study) (Jalabert et al., '74; Potts and Phelps, '95; Kwon et al., 2000), the differences in efficiency of the treatments have to be searched in the developmental events targeted by the treatments, the endocrine and genetic mechanisms of sex determination and differentiation taking place during this precocious phase and the genotypic differences of tested fish.

As androgen (Golan and Levavi-Sivan, 2014) and estrogen (Kawahara and Yamashita, 2000; Singh, 2013) receptors are involved in hormone-induced sex reversal, their expression is a prerequisite to successfully override genetic sex determination by exogenous hormone exposure. In tilapia, the two androgen receptors ( $\operatorname{ar} 1$ and $\operatorname{ar} 2$ ) are expressed at a low level at the onset of gonadal development (from $9 \mathrm{dpf}$ ) and the three estrogen receptors (esr 1, esr $2 a$, and esr $2 b$ ) at a high level, similarly in XX and XY (Ijiri et al., 2008). Before the formation of the gonad, the target of exogenous hormones in the mechanism of sex reversal could be the brain or the primordial germ cells and their environment (Kobayashi and Iwamatsu, 2005; Rougeot et al., 2008a). Esr 1 and esr $2 a$ are expressed in the brain of both XX and $\mathrm{XY}$ tilapia larvae from hatching (4 dpf). In contrast, the expression of androgen receptors is differentially initiated in $\mathrm{XX}$ and XY. Ar1 transcripts are detected from $4 \mathrm{dpf}$ in XY but not before $29 \mathrm{dpf}$ in $\mathrm{XX}$ and ar2 is expressed from $9 \mathrm{dpf}$ in $\mathrm{XY}$ and from $4 \mathrm{dpf}$ in XX (Sudhakumari et al., 2005). Even though both androgen and estrogen receptivities seem to be acquired early during fish development, a quantitative study of the expression of steroid receptors during tilapia embryogenesis and embryonic sex reversal would clarify their role in mediating the action of exogenous hormones, and we cannot exclude that a differential expression of the estrogen and androgen receptors may account for the differences in treatment potencies and genotype sensitivities. More specifically, the absence of one of the two ar in the brain of developing XX embryos could be responsible for their low susceptibility to androgen-induced sex reversal.

In natural sexual differentiation in tilapia, androgens do not appear to play an important role (Nagahama, 2005). The most potent natural androgen, $11 \mathrm{KT}$, is not synthesized in the differentiating testis before $29 \mathrm{dpf}$ (Ijiri et al., 2008). This suggests that androgen-signaling pathways may not be fully developed in embryos, explaining the low potency of androgens in embryonic sex-reversing treatments. In contrast, estrogens play a critical role in ovarian differentiation and the lack of estrogens during the period of gonad differentiation is responsible for testis development (Guiguen et al., '99; Kwon et al., 2000; Nagahama, 2005). Given that and the wide diversity of other estrogen functions during ontogenesis (Hao et al., 2013), estrogen-signaling pathways establish early during development and can therefore be used by exogenous hormones to override natural processes.

As the treatment of XX embryos with an aromatase inhibitor induced up to $10 \%$ sex inversion, it is proposed that aromatase and estrogens could play a role in sexual differentiation during embryogenesis. In Nile tilapia, brain aromatase was up-regulated 


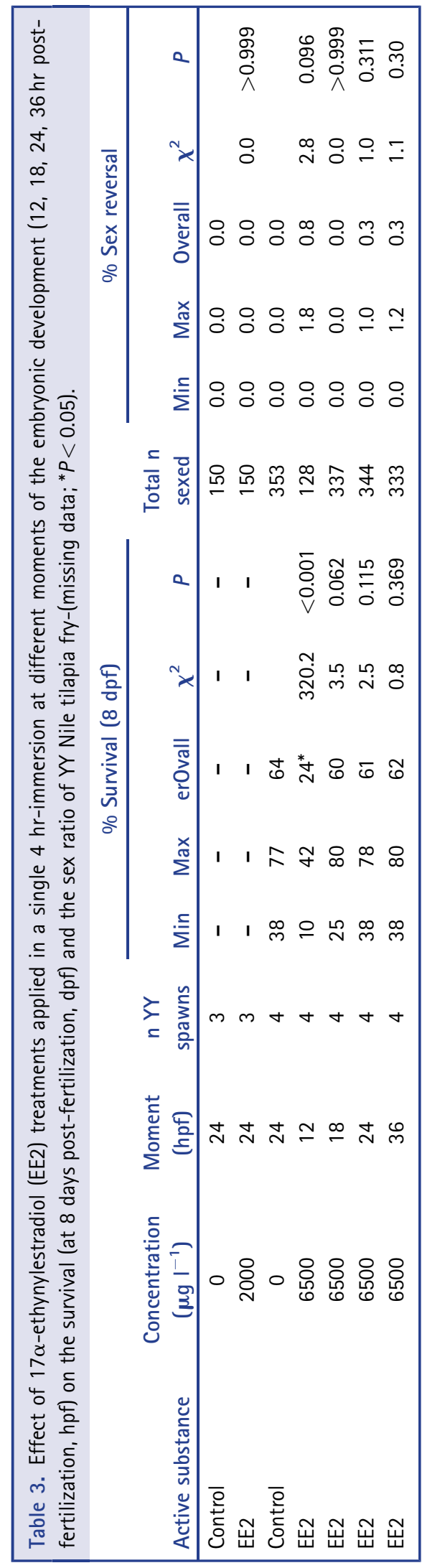

in a dose-dependent manner in EE2-treated XY and YY embryos at $4 \mathrm{dpf}$ (submitted manuscript), suggesting a possible modification of the brain sexual differentiation that could consequently play a role in the development of the sexual phenotype. Both aromatizable (MT) and non-aromatizable (dihydrotestosterone) androgens in vitro inhibited aromatase activity in ovarian microsomes of tilapia (Golan and Levavi-Sivan, 2014) suggesting that exogenous androgens administered during the differentiation of the gonad exerted an inhibitory action on aromatase activity which could be part of the mechanism of early masculinization. However, since masculinization rates were only 10\% in XX spawns and no sex reversal was observed in YY spawns, changes in the expression or activity of brain aromatase could not be the sole factor involved in the mechanism of embryonic sex reversal.

Results of feminization in XY and the absence of susceptibility to EE2 embryonic treatments in YY can be explained by the presence on the $\mathrm{X}$ chromosome of a female inducer or alternatively the presence on the $\mathrm{Y}$ of a female repressor (or male inducer). In any case, the mechanism of embryonic sex reversal must rely on a balance between the action of the exogenous steroids and the upstream genetic factors involved in the sex-determining and differentiating cascade. Such a hormonal-genetic balance can be exemplified with $d m r t 1$ that is a conserved male marker specifically expressed in testes. Evidence of the importance of this gene in testicular differentiation was underlined by the discovery of its homolog $d m y$ as the major sex-determinant in medaka (Matsuda et al., 2002). In tilapia, $d m r t 1$ is expressed specifically in the Sertoli cell lineage from 10 dpf (Ijiri et al., 2008; Kobayashi et al., 2008). It is upregulated in the differentiating testis of MT-induced XX males and repressed in the differentiating ovary of EE2-induced XY females (Kobayashi et al., 2008), while XX fish carrying extra copies of dmrt1 as a transgene develop into males (Nagahama, 2005). Dmrt1 (or an homolog) is not the major sex determinant in tilapia (Volff et al., 2003) but a sex determinant upstream from $d m r t 1$ could be expressed during embryogenesis and prevents exogenous estrogen to override the genetic sex determinism when present in two copies.

In conclusion, as shown in a previous study using thermal treatments (Rougeot et al., 2008b), it is possible to artificially reverse the sex differentiation pathway of tilapia during embryogenesis, before the gonad differentiating period. Our results reinforced the hypothesis of an action of exogenous hormones on brain sexual differentiation or on primordial germ cells and their environment, and the important role of aromatase in sex differentiation mechanisms. Nevertheless, as estrogen treatments failed to reverse $Y Y$ fish to females, the hypothesis of a sex determinant linked to the $\mathrm{Y}$ chromosome preventing the female pathway when present in two copies, or a gene present on the $\mathrm{X}$ chromosome needed for the development of a female phenotype, is suggested. The investigation of the genetic and 
endocrine mechanisms involved in embryonic sex reversal would provide valuable insights on sex determination and early sex differentiation in the Nile tilapia.

\section{ACKNOWLEDGMENTS}

We thank Christian Prignon and Denis Gustin for their precious help in fish housing and sex-ratio analysis. V. G. was a Ph.D. grant holder from FRIA-FNRS (Fonds pour la Formation à la Recherche dans l'Industrie et dans l'Agriculture). P. M., U. B., and D. A. were M.Sc. grant holders from ARES-CCD (Académie de Recherche et d'Enseignement Supérieur - Comission de la Coopération au Développement).

\section{LITERATURE CITED}

Beardmore JA, Mair GC, Lewis RI. 2001. Monosex male production in finfish as exemplified by tilapia: applications, problems, and prospects. Aquaculture 197:283-301.

Blázquez M, Somoza GM. 2010. Fish with thermolabile sex determination (TSD) as models to study brain sex differentiation. Gen Comp Endocrinol 166:470-477.

D'Cotta H, Fostier A, Guiguen Y, Govoroun M, Baroiller JF. 2001. Aromatase plays a key role during normal and temperature-induced sex differentiation of tilapia Oreochromis niloticus. Mol Reprod Dev 59:265-276.

Devlin RH, Nagahama Y. 2002. Sex determination and sex differentiation in fish: an overview of genetic, physiological, and environmental influences. Aquaculture 208:191-364.

Gennotte V, Sawadogo P, Milla S, et al. 2012. Cortisol is responsible for positive and negative effects in the ovarian maturation induced by the exposure to acute stressors in Nile tilapia, Oreochromis niloticus. Fish Physiol Biochem 38:16191626.

Gilling CJ, Skibinski DOF, Beardmore JA. 1996. Sex reversal of tilapia fry by immersion in water containing estrogens. In: Pullin RSV, Lazard J, Legendre M, Amon Kothlas JB, Pauly D, editors. The Third International Symposium on Tilapia in Aquaculture. Makati City, Philippines: ICLARM. p 314-319.

Golan M, Levavi-Sivan B. 2014. Artificial masculinization in tilapia involves androgen receptor activation. Gen Comp Endocrinol 207: 50-55.

Guerrero RD, Shelton WL. 1974. An aceto-carmine squash method for sexing juvenile fishes. Prog Fish Cult 36:56.

Guiguen Y, Baroiller JF, Ricordel MJ, et al. 1999. Involvement of estrogens in the process of sex differentiation in two fish species: the rainbow trout (Oncorhynchus mykiss) and a tilapia (Oreochromis niloticus). Mol Reprod Dev 54:154-162.

Hao R, Bondesson M, Singh AV, et al. 2013. Identification of estrogen target genes during zebrafish embryonic development through transcriptomic analysis. PLoS ONE 8:e79020.

Herrera AA, Cruz RR. 2001. Developmental biology of the supermale YY tilapia (Oreochromis niloticus): histogenesis of the reproductive system. Sci Diliman 13:33-40.
Ijiri S, Kaneko H, Kobayashi T, et al. 2008. Sexual dimorphic expression of genes in gonads during early differentiation of a teleost fish, the Nile tilapia Oreochromis niloticus. Biol Reprod 78:333-341.

Iwamatsu T, Kobayashi H, Hamaguchi S, Sagegami R, Shuo T. 2005. Estradiol-17 $\beta$ content in developing eggs and induced sex reversal of the medaka (Oryzias latipes). J Exp Zool 303A:161-167.

Iwamatsu T, Kobayashi H, Yamashita M. 2006. Sex reversal in medaka treated in vitro with $17 \alpha$-methyldihydrotestosterone during oocyte maturation. Dev Growth Diff 48:59-64.

Jalabert B, Moreau J, Planquette P, Billard R. 1974. Déterminisme du sexe chez Tilapia macrochir et Tilapia nilotica: action de la méthyltestostérone dans l'alimentation des alevins sur la différentiation sexuelle; proportion des sexes dans la descendance des mâles "inversés". Ann Biol Anim Bioch Biophys 14:729-739.

Kawahara T, Yamashita I. 2000. Estrogen-independent ovary formation in the medaka fish, Oryzias latipes. Zool Sci 17:65-68.

Kikuchi K, Hamaguchi S. 2013. Novel sex-determining genes in fish and sex chromosome evolution. Dev Dyn 242:339-353.

Kobayashi H, Iwamatsu T. 2005. Sex reversal in the medaka Oryzias latipes by brief exposure of early embryos to estradiol-17 $\beta$. Zool Sci 22:1163-1167.

Kobayashi T, Kajiura-Kobayashi H, Guan G, Nagahama Y. 2008. Sexual dimorphic expression of DMRT1 and Sox9a during gonadal differentiation and hormone-induced sex reversal in the teleost fish Nile tilapia (Oreochromis niloticus). Dev Dyn 237:297-306.

Kobayashi T, Kajiura-Kobayashi H, Nagahama Y. 2003. Induction of XY sex reversal by estrogen involves altered gene expression in a teleost, tilapia. Cytogenet Genome Res 101:289-294.

Kwon JY, Haghpanah V, Kogson-Hurtado LM, McAndrew BJ, Penman DJ. 2000. Masculinization of genetic female Nile tilapia (Oreochromis niloticus) by dietary administration of an aromatase inhibitor during sexual differentiation. J Exp Zool 287:46-53.

Matsuda M, Nagahama Y, Shinomiya A, et al. 2002. DMY is a Yspecific DM-domain gene required for male development in the medaka fish. Nature 417:559-563.

Morrison CM, Miyake T, Wright JRJ. 2001. Histological study of the development of the embryo and early larva of Oreochromis niloticus (pisces: Cichlidae). J Morphol 247:172-195.

Nagahama Y. 2005. Molecular mechanisms of sex determination and gonadal sex differentiation in fish. Fish Physiol Biochem 31:105109.

Pandian TJ, Sheela SG. 1995. Hormonal induction of sex reversal in fish. Aquaculture 138:1-22.

Phelps RP, Popma TJ. 2000. Sex reversal of tilapia. In: Costa-Pierce BA, Rakocy JE, editors. Tilapia aquaculture in the Americas, vol 2. Baton Rouge, LA: The World Aquaculture Society. p 34-59.

Poonlaphdecha S, Pepey E, Huang SH, et al. 2011. Elevated amh gene expression in the brain of male tilapia (Oreochromis niloticus) during testis differentiation. Sex Dev 5:33-47.

Potts AC, Phelps RP. 1995. Use of diethylstilbestrol and ethynylestradiol to feminize Nile tilapia Oreochromis niloticus (L.) in an outdoor environment. J of Appl Ichthyol 11:111-117. 
Rosenstein S, Hulata G. 1992. Sex reversal in the genus Oreochromis: 1. Immersion of eggs and embryos in oestrogen solutions is ineffective. Aquacult Fish Manage 23:669-678.

Rougeot C, Kanfitine SY, Prignon C, Gennotte V, Mélard C. 2008a. Early sex reversal during the embryonic development in the nile tilapia. Cybium 32:104-105.

Rougeot C, Prignon C, Ngouana Kengne, Mélard CV. 2008b. Effect of high temperature during embryogenesis on the sex differentiation process in the Nile tilapia, Oreochromis niloticus. Aquaculture 276:205-208.

Siegfried KR. 2010. In search of determinants: gene expression during gonadal sex differentiation. J Fish Biol 76:1879-1902.

Singh AK. 2013. Introduction of modern endocrine techniques for the production of monosex population of fishes. Gen Comp Endocrinol 181:146-155.
Sudhakumari CC, Senthilkumaran B, Kobayashi T, et al. 2005. Ontogenic expression patterns of several nuclear receptors and cytochrome $\mathrm{P} 450$ aromatases in brain and gonads of the Nile tilapia Oreochromis niloticus suggests their involvement in sex differentiation. Fish Physiol Biochem 31:129-135.

Tsai CL, Wang LH, Chang CF, Kao CC. 2000. Effects of gonadal steroids on brain serotonergic and aromatase activity during the critical period of sexual differentiation in tilapia, Oreochromis mossambicus. J Neuroendocrinol 12:894-898.

Volff JN, Kondo M, Schartl M. 2003. Medaka dmY/dmrt1Y is not the universal primary sex-determining gene in fish. Trends Genet 19:196-199.

Wassermann GJ, Afonso LOB. 2003. Sex reversal in Nile tilapia (Oreochromis niloticus Linnaeus) by androgen immersion. Aquacult Res 34:65-71.

J. Exp. Zool. 